\title{
Risk Factors Associated with Injury and Mortality from Paediatric Low Speed Vehicle Incidents: A Systematic Review
}

\author{
Anne Paul Anthikkat, ${ }^{1}$ Andrew Page, ${ }^{1}$ and Ruth Barker ${ }^{2}$ \\ ${ }^{1}$ Discipline of Epidemiology and Biostatistics, School of Population Health, University of Queensland, Herston, QLD 4006, Australia \\ ${ }^{2}$ Paediatric Emergency Medicine Unit, Queensland Injury Surveillance Unit (QISU), Mater Health Services, Level 1 Whitty Building, \\ Raymond Terrace, South Brisbane, QLD 4101, Australia
}

Correspondence should be addressed to Andrew Page; a.page@uws.edu.au

Received 21 December 2012; Accepted 21 April 2013

Academic Editor: Edward Y. Lee

Copyright ( 2013 Anne Paul Anthikkat et al. This is an open access article distributed under the Creative Commons Attribution License, which permits unrestricted use, distribution, and reproduction in any medium, provided the original work is properly cited.

Objective. This study reviews modifiable risk factors associated with fatal and nonfatal injury from low-speed vehicle runover (LSVRO) incidents involving children aged 0-15 years. Data Sources. Electronic searches for child pedestrian and driveway injuries from the peer-reviewed literature and transport-related websites from 1955 to 2012. Study Selection. 41 studies met the study inclusion criteria. Data Extraction. A systematic narrative summary was conducted that included study design, methodology, risk factors, and other study variables. Results. The most commonly reported risk factors for LSVRO incidents included age under 5 years, male gender, and reversing vehicles. The majority of reported incidents involved residential driveways, but several studies identified other traffic and nontraffic locations. Low socioeconomic status and rental accommodation were also associated with LSVRO injury. Vehicles were most commonly driven by a family member, predominantly a parent. Conclusion. There are a number of modifiable vehicular, environmental, and behavioural factors associated with LSVRO injuries in young children that have been identified in the literature to date. Strategies relating to vehicle design (devices for increased rearward visibility and crash avoidance systems), housing design (physical separation of driveway and play areas), and behaviour (driver behaviour, supervision of young children) are discussed.

\section{Introduction}

Low-speed vehicle runover (LSVRO) injuries have been variably categorized as "rollover," "backover," "driveway," or other "nontraffic" pedestrian injuries. They predominantly occur in nontraffic (off-road) settings, but not exclusively so, and as such have different antecedents to high-speed vehicle and traffic-related pedestrian injuries. Investigation and reporting of off-road vehicular incidents vary by locality, and a lack of standardised definitions, coding, and reporting makes LSVRO incidents difficult to find in routine data sources.

Previous studies on child pedestrian injuries have identified specific contexts and antecedents relating to vehicular, environmental, and behavioural factors [1]. Injuries in children result in a significant economic burden to the health system due to long-term sequelae and ongoing disability amongst survivors [2]. In addition to the economic cost, there are significant psychological impacts on parents and carers $[3,4]$. LSVRO incidents carry a significant risk of head and neck injury and have a high case fatality [5-8] with a 10fold increase in mortality in children under 5 years of age [9].

Worldwide, studies on LSVRO incidents have been conducted over several decades [10-14]. These studies have identified a variety of sociodemographic, vehicular, environmental, and behavioural factors that predispose to LSVRO injury. However, there has been to date no peer-reviewed, systematic review on LSVRO incidents examining the consistency of these factors across different settings. The aim of this systematic review is to (i) identify common modifiable risk factors for paediatric LSVRO injuries across different 
settings and localities, (ii) identify specific risk factors that have been reported for particular settings or localities, and (iii) recommend potential countermeasures for reducing the frequency and severity of such events in the paediatric population.

\section{Methods}

2.1. Data Sources. Five electronic databases (PubMed, Scopus, CINAHL, Embase, and Web of Science) were searched for English language publications on child pedestrian injuries in the paediatric population for the period 1955-October 2012. Additional searches were also conducted using Google Scholar for unpublished studies, conference presentations, and reports, and also the databases of Transport Research Laboratory (TRL) in the United Kingdom (UK), Centers of Disease Control (CDC) in the United States (US), and National Highway Traffic Safety Administration (NHTSA) in the US. Secondary searches of reference lists were also conducted for potential articles.

2.2. Search Terms. The broad search term used was "child pedestrian injuries" and in subsequent additional searches included the keywords "driveway injuries" and "nontraffic injuries." MesH terms used in Embase were ("child/exp" OR “child” OR “children/exp” OR “children” OR "paediatrics/exp" OR "paediatrics" OR "paediatrics/exp” OR "paediatrics" OR “infant/exp” OR “infant”) AND ("driveway” OR "garage" OR “carport”) AND ("accident/exp" OR "accident" OR “car/exp” OR “car” OR "automobile/exp” OR "automobile").

2.3. Identification of the Literature. This review considered articles which mentioned injuries due to slow-moving vehicles, or vehicles reversing or rolling, or injuries occurring in various locations (e.g., driveways, parking lots, other nontraffic situations, and verge of traffic), or due to a child falling from a slow-moving vehicle. Titles and abstracts were read to identify papers for inclusion. Full-text articles, reviews, and reports were then obtained to extract relevant study factors (Figure 1). Assessment of eligibility of studies and extraction of data from study reports were conducted by authors APA and AP. Consensus was used to classify articles based on type of study design. Abstracts without full text, case studies, opinion pieces, and articles with information only on injury outcomes and treatments rather than antecedent factors were excluded.

For this review, LSVRO cases were defined as children and adolescents aged 18 years or younger who sustained fatal or nonfatal injuries resulting from an impact with a motorised road vehicle moving at low speed either in a "nontraffic" setting (e.g., driveways, yard, garage, car park, and access road) or in a location where vehicles are moving into or out of traffic flow (traffic verge). Information on LSVRO incidents in the age-specific subgroups (0-5, 6-15, and $\geq 16$ years) was extracted separately from studies as injury mechanisms that occurred in older children, adolescents, and young adults were different from those in young children.

2.4. Data Extraction and Synthesis. Data on key variables such as study design, methodology, risk factors, and other relevant variables for LSVRO injuries and fatalities were extracted using a standardised data extraction form. Studies were broadly classified as descriptive or analytic and individual level or aggregate (ecologic). For analytic studies, where groups exposed or not exposed to a given risk factor were compared, relative risk estimates (either OR or RR) were extracted. In descriptive studies, where no comparators were reported (e.g., in case-series studies) the number of cases (and proportion of total cases) with a given risk factor or characteristic was extracted. A systematic narrative summary of risk factors identified from each of these studies is outlined in this review. Meta-analysis was not appropriate due to variability in methods and measures between the studies; however identified studies could be grouped in terms of common domains relating to sociodemographic, vehicular, environmental, and behavioural factors.

\section{Results}

3.1. Identified Studies. Forty one articles met the inclusion criteria for LSVRO injuries predominantly in nontraffic settings and form the basis of this review (Tables 1-3). Of the 41 studies identified, ten studies investigated nonfatal injury (Table 1), 15 studies investigated fatal injury (Table 2), and 16 studies investigated both nonfatal and fatal injury (Table 3). Studies were predominantly conducted in the USA (16 studies), Australia (15 studies), and New Zealand (NZ) (8 studies); one study was conducted in Canada andone study reported from Austria. The majority of studies (38 of 41 studies) were case-series designs without a comparator group. There were two case-control studies (NZ) and one aggregate cross-sectional study (US). The majority of studies (31 of 41) appeared in the peer-reviewed literature, although ten government or commissioned reports were also identified.Fourcase reports on injury outcomes and treatment of driveway injuries, twofrom UK $[46,47]$ and twofrom USA $[48,49]$, were excluded.

\subsection{Sociodemographic Risk Factors}

3.2.1. Age. Twenty four of the 41 studies reported on LSVRO injuries in children aged up to 15 years, seven studies examined LSVRO injuries in children, adolescents, and young adults aged up to 20 years $[7,9,13,18,28,32,41]$, and tenstudies $[5,8,14,23-27,29,42]$ reported solely on children aged up to 5 years.

Of the 31 studies where children older than 5 years were included, a higher proportion of LSVRO incidents were found in children aged $\leq 5$ years when compared to children aged $\geq 5$ years (range $35 \%-73 \%$ of cases). This was particularly noted for 16 of the 25 studies examining driveway-related LSVRO incidents. Within the 31 studies that included children aged up to 15 years, 15 studies 


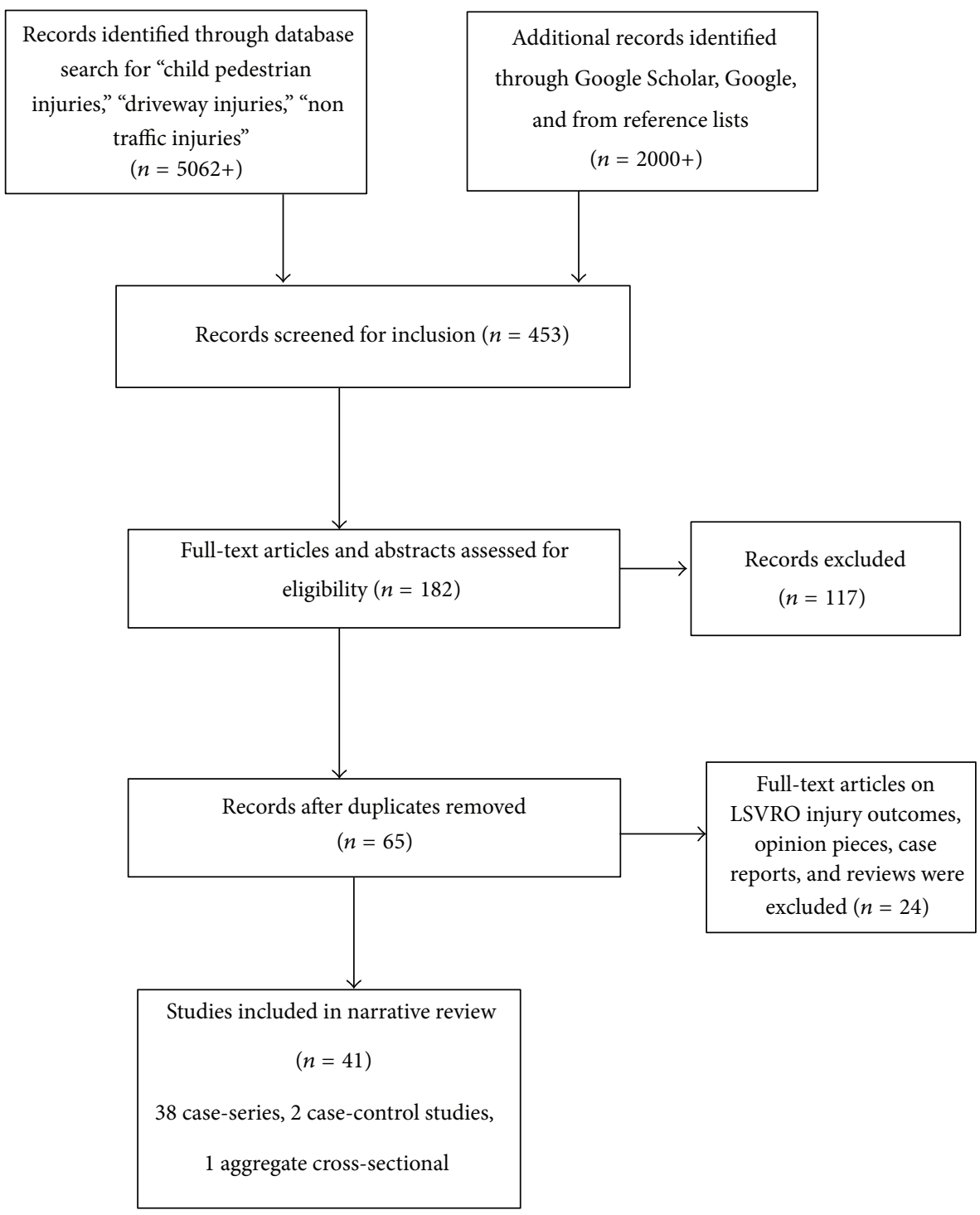

FIGURE 1: Steps for inclusion of articles in the systematic narrative review.

$[5,14,15,20,21,23,24,28-31,34-36,42]$ noted that children aged $0-2$ years (range $55 \%-73 \%$ of cases) comprised the highest proportion of LSVRO injuries.

3.2.2. Sex. 31 studies amongst the 41 studies investigated sex differences, the majority of which (27 of 31 studies) reported a higher proportion of injuries among boys (range 52\%-86\%). Twostudies on driveway incidents $[7,26]$ reported no sex differences, and two studies from US and NZ $[14,44]$ reported a higher proportion of girls than boys in nontraffic incidents mainly in driveways.Two studies showed a higher proportion of male children involved in LSVRO injuries that occurred in parking lots $[21,41]$.

When analyzed by mechanism,one study showed that LSVRO incidents caused by falling from a moving vehicle [8] involved a higher proportion of male children. Nadler et al. reported a higher proportion of female children injured when the vehicle was moved by a child shifting the vehicle out of gear compared to when an adult was the driver [42].

3.2.3. Race and Ethnicity. Of the 41 studies identified in the review, 11 studies investigated race and/or ethnicity as a factor associated with low-speed vehicle incidents $[11,12,14,15,23$, $24,27,36,37,40,43]$.

Studies from NZ found that a higher proportion of driveway-related LSVRO injuries were reported in Pacific (range 26-49\%) and Maori (range 25-48\%) children [15, 24, $36,37,40]$. Onestudy from the US found a lower proportion of cases in Hispanic compared to non-Hispanic children [12] while a recent US study reported a higher proportion of cases involving Hispanic children [14]. A case-series from US reported proportionately more cases among white children when compared to black children [11]. 


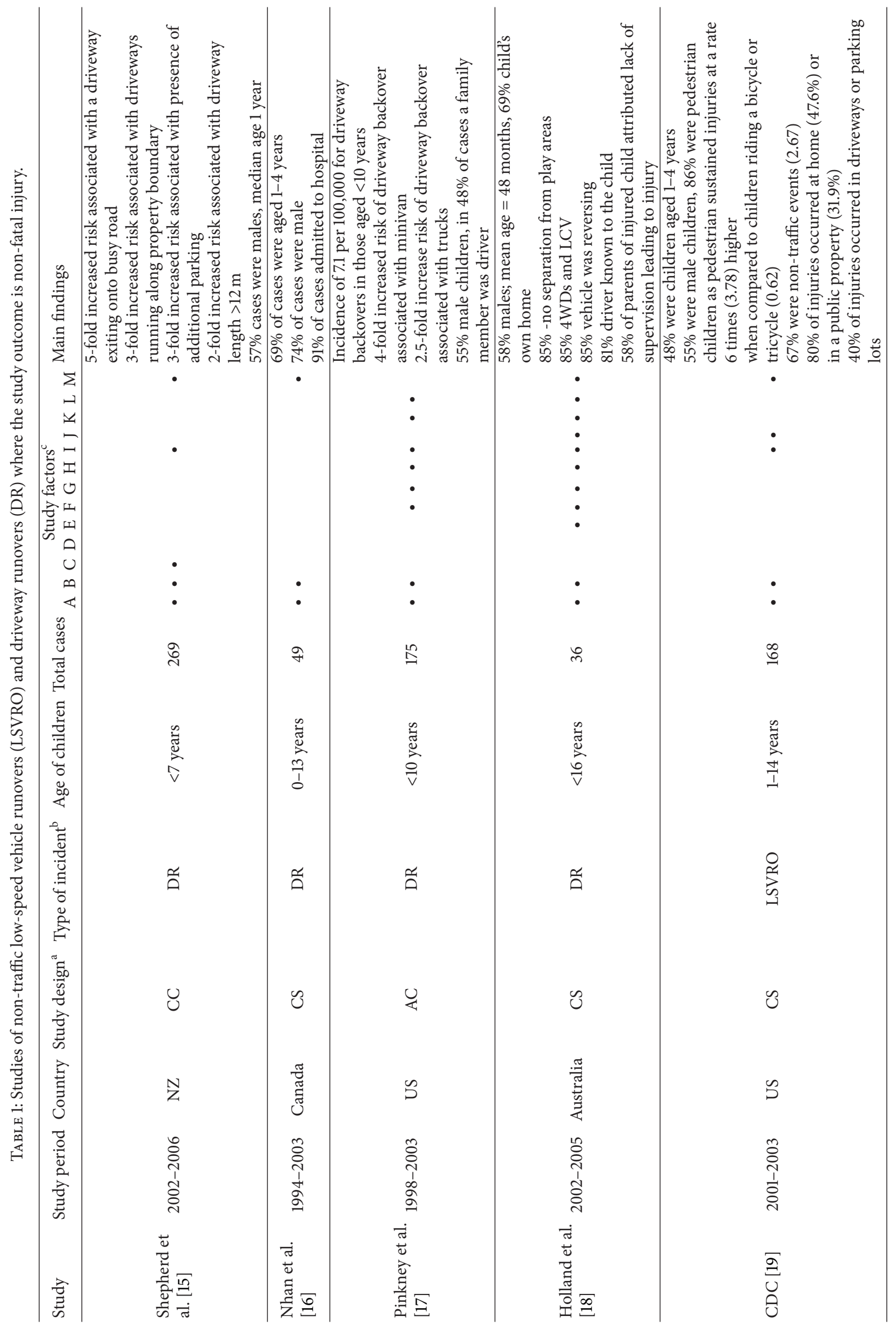




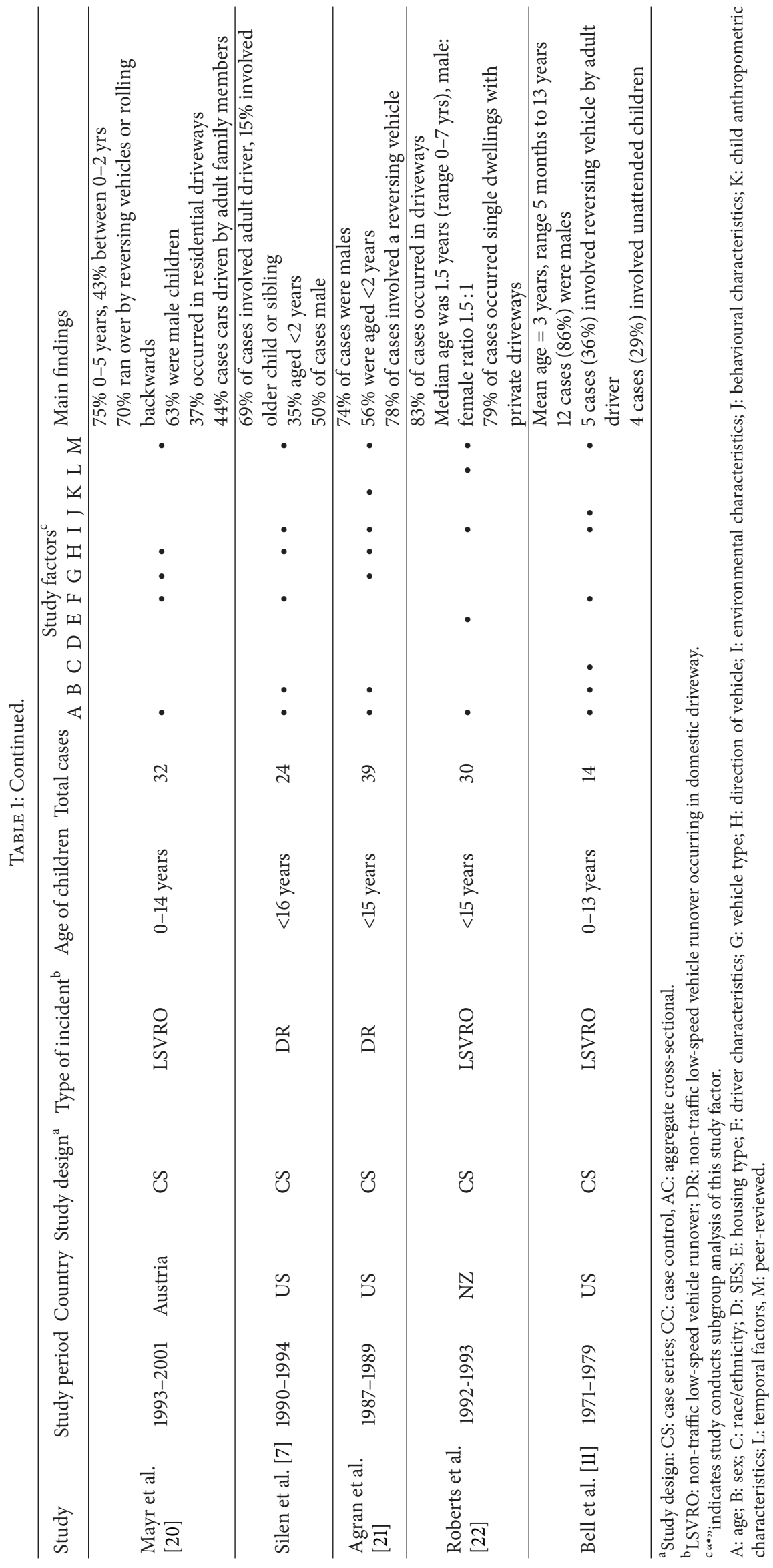




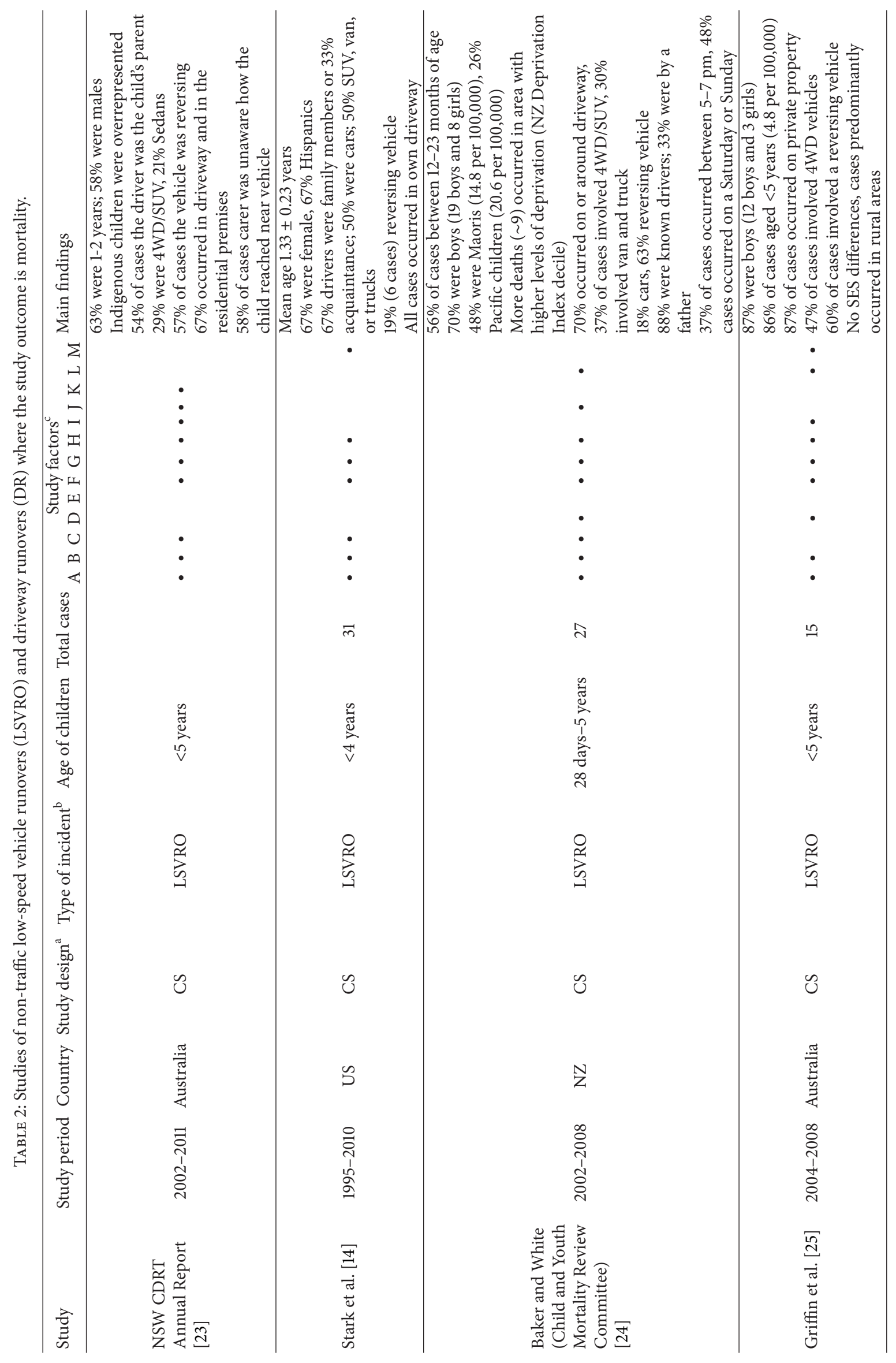




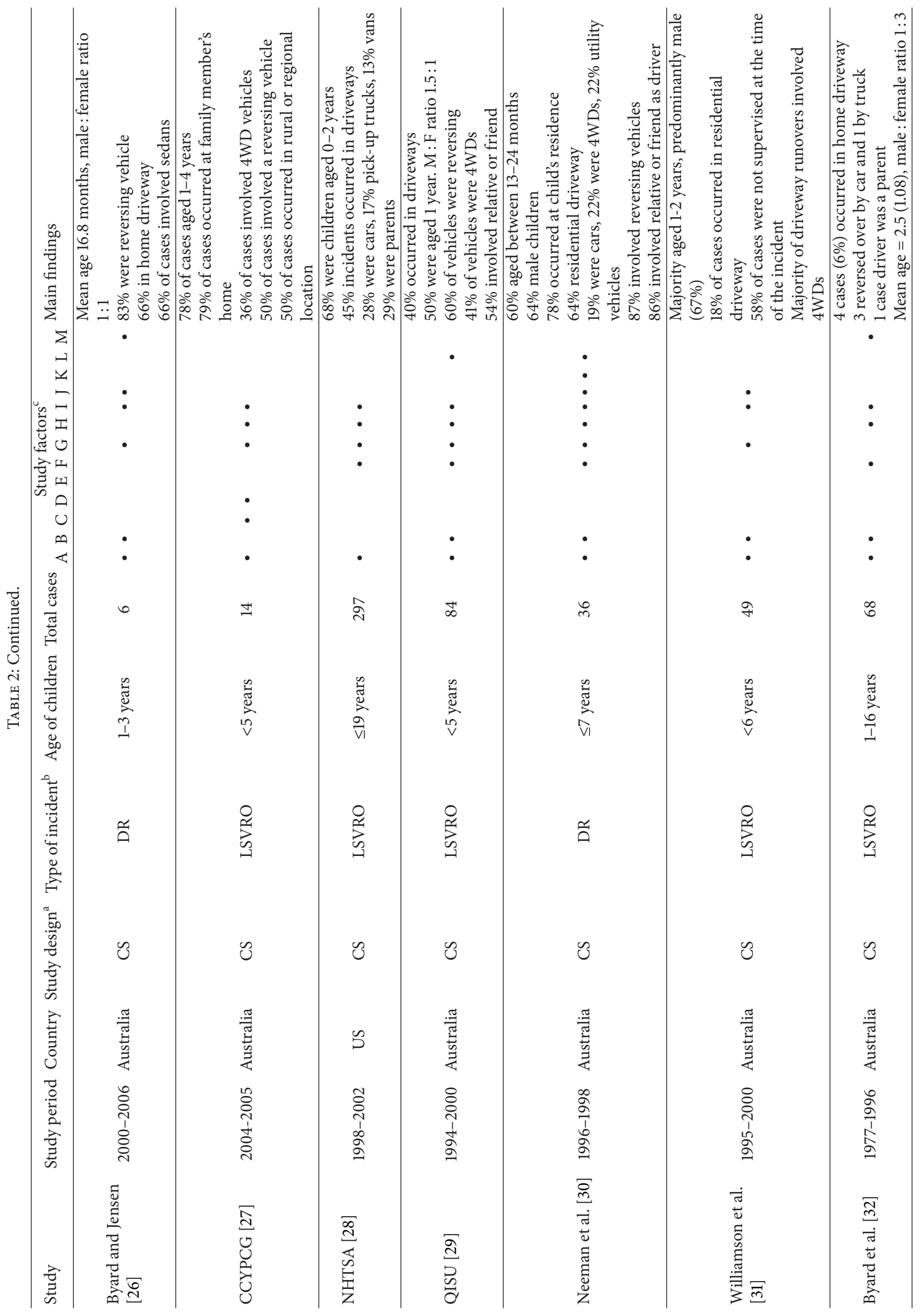




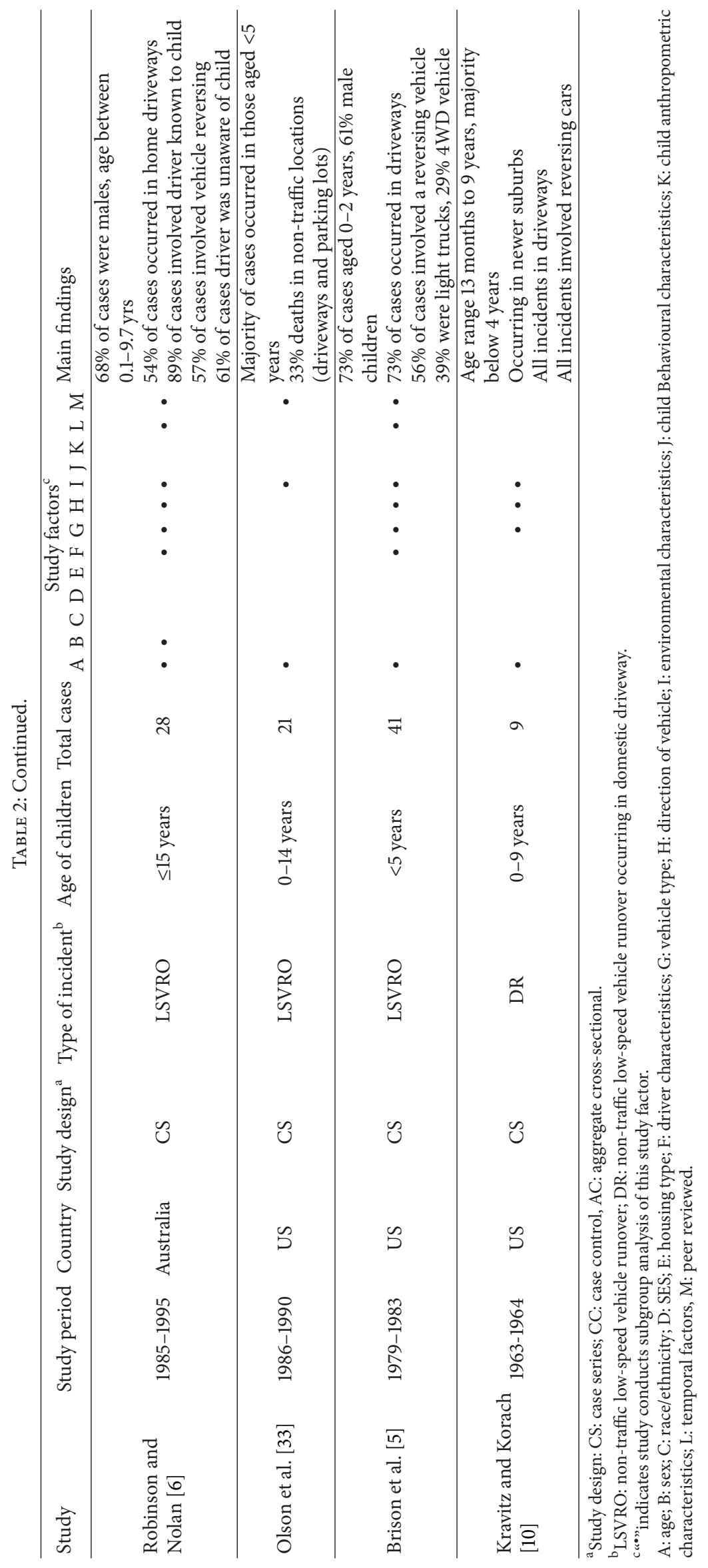




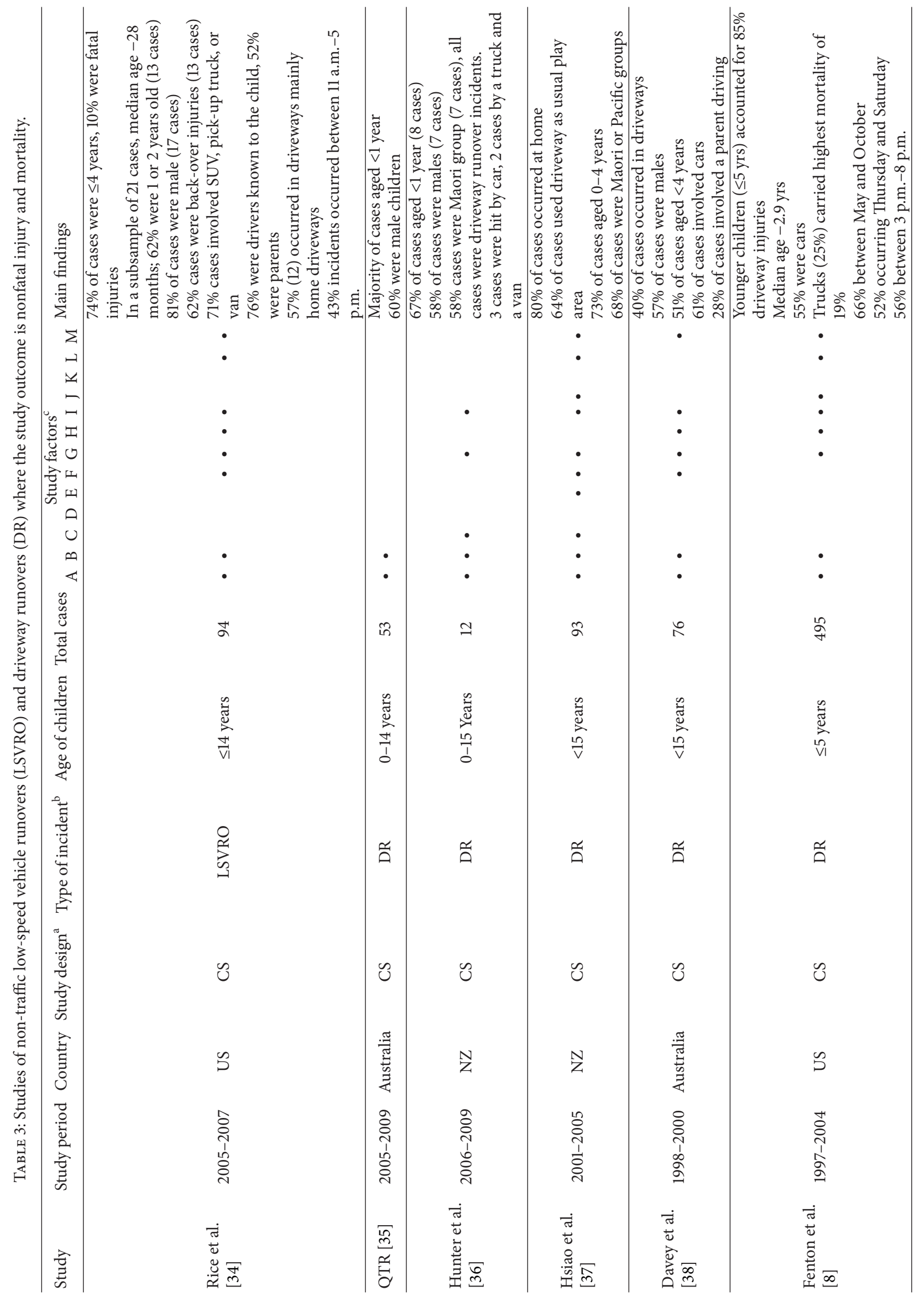




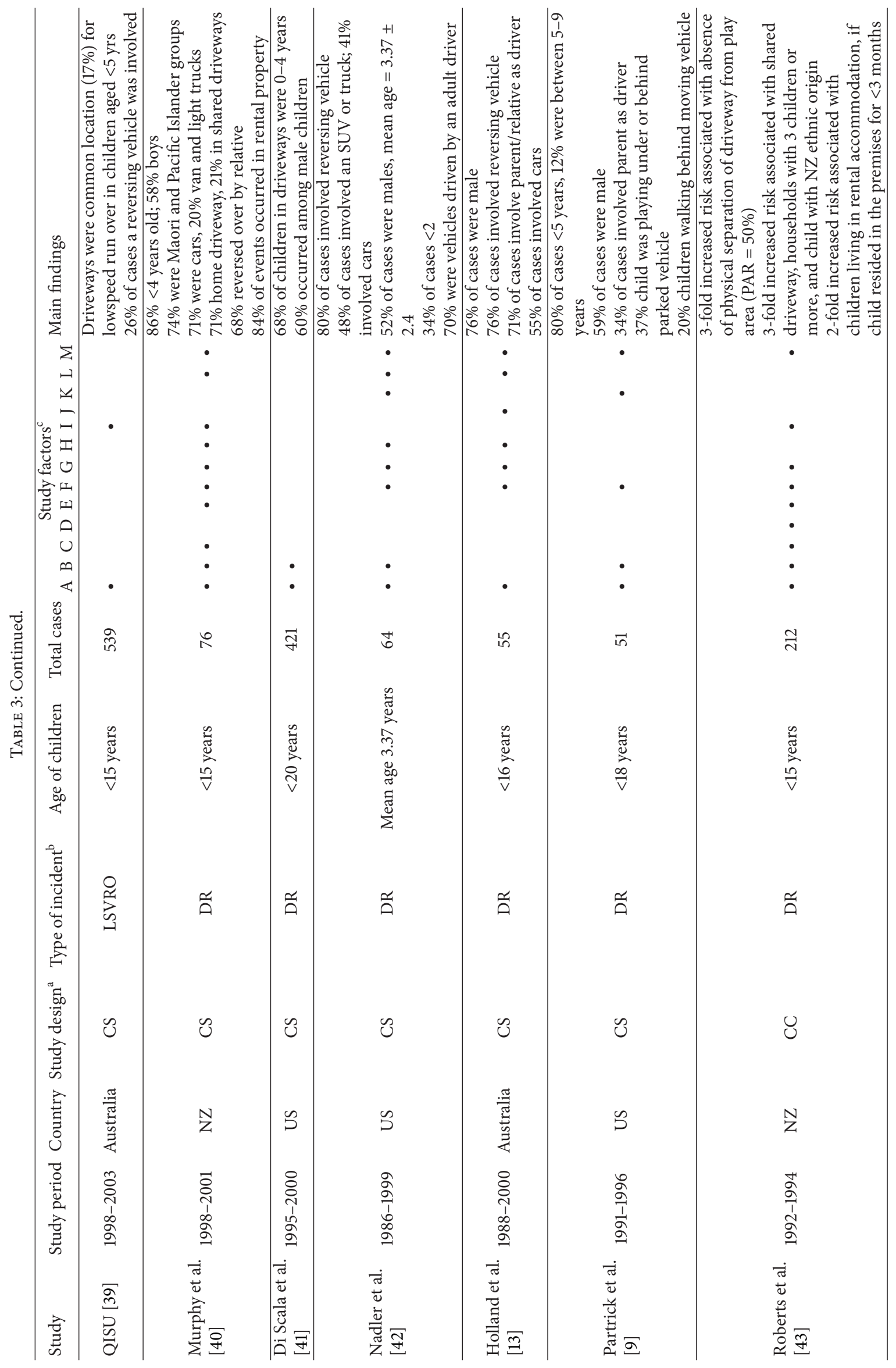




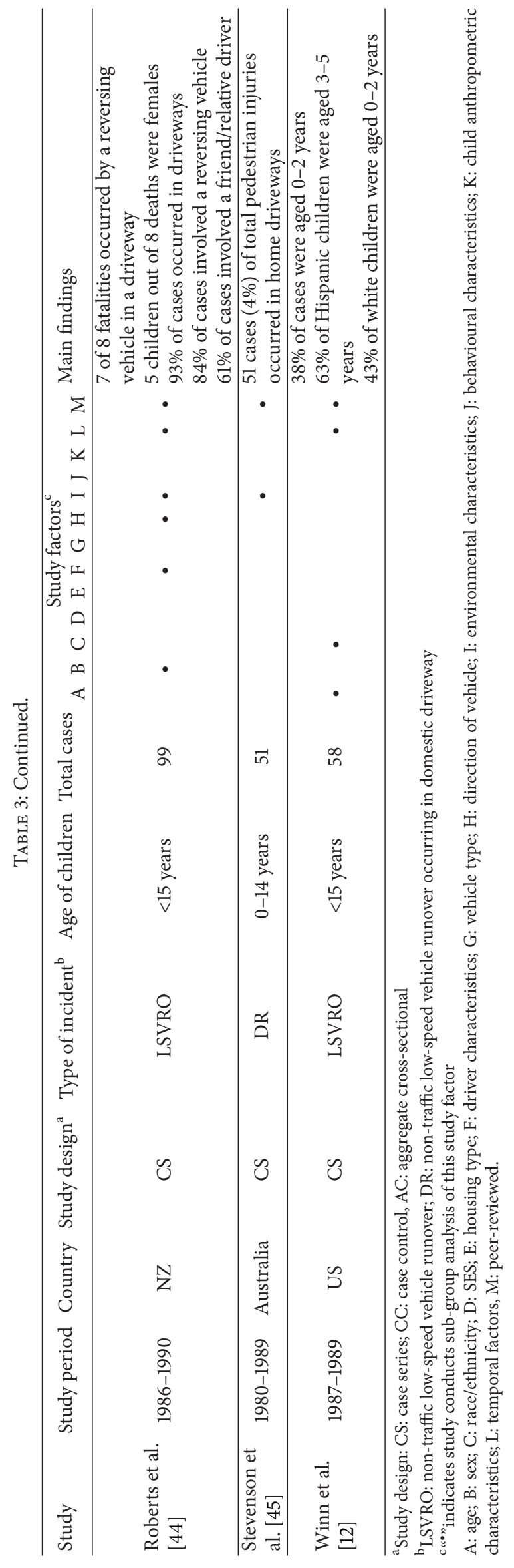


3.2.4. Socioeconomic Status (SES). Seven of eight studies [18, $22,24,25,27,37,40,43]$ that investigated SES found that LSVRO incidents were more common in lower than in higher SES groups as identified by area-based measures [24, 27], individual-level income, [43], or whether living in a rental property or not $[18,22,37,40,43]$. The strongest evidence for low SES as a risk factor comes from the case-control study of Roberts et al. from Auckland (NZ) [43]. Assessment of SES was based on parental interview and allocation of SES status according to parental occupation.

3.2.5. Number of Children in Household. One study [43] reported a 3 -fold increase in risk for driveway-related LSVRO incidents where there were three or more children under the age of 5 years in one household compared to when two or less children were in the household.

3.2.6. Driver Characteristics. Nineteen studies of LSVRO reported whether or not an adult driver was in control of the vehicle at the time of the incident (range 34-88\%) and whether the driver was known to the child (range 41\%-89\%). However, several studies reported incidents that involved driverless vehicles $[5,6,28,38]$ or vehicles being inadvertently set in motion by children (range 10-15\%) [7, 9, 18, 42]. In 18 of 23 studies investigating driver identity, a family member (parent, grandparent, sibling, or relative) was the driver (range 36-67\%) and 13 of these studies reported proportions of cases where the driver was either the mother or father of the injured child. Amongst these, six studies $[5,6,24,25,30,37]$ noted that fathers (range 20\%-40\%) were proportionately more frequently involved in an LSVRO incident when compared to mothers. Other drivers identified were neighbours, friends, commercial drivers, and visiting tradesmen.

\subsection{Environmental Risk Factors}

3.3.1. Location of Incident. Thirty seven articles identified LSVRO injuries primarily on the basis of the nontraffic setting of the incident. Four studies also mentioned LSVRO injuries that occurred in traffic locations [25, 28, 30, 34]. Of the 41 studies investigating child pedestrian incidents in various locations, 15 studies investigated child pedestrian injuries relating to incidents in a range of locations with a subgroup of nontraffic incidents. 26 studies specifically focussed on child pedestrian incidents occurring in nontraffic locations. The most common nontraffic location investigated across these 26 studies was residential/home driveways with nine studies solely investigating paediatric LSVRO driveway incidents.

Of the 26 studies on driveways, 17 studies investigated nontraffic child pedestrian injuries relating to residential driveways (including friend's, neighbour's, and other residential locations) with proportions ranging from $17 \%$ to $93 \%$ $[7-10,13,15,17,18,26,30,35-38,40,42,43]$ and nine studies specifically reported the child's "home driveway" as a common location of injury (range $17 \%-71 \%$ ) $[6,14,19,23$, $24,28,29,32,34]$.
Of the 41 studies, 15 studies reported the location of child pedestrian incidents occurring in nontraffic settings other than on a residential driveway: garages or carports $[6,30,39]$, parking lots or car parks [16, 19-22, 28, 34, 41, 44], a holiday home [6], a company yard [6], a caravan park or camping ground [30], sidewalks [20, 28, 41], paddock on farm [30], other commercial premises $[5,6,19,30]$, and other off-road locations [28, 31, 33] and a general description of incidents occurring in "newer suburbs." [10].

3.3.2. Driveway Characteristics. Of 26 studies that included residential driveway-related LSVRO cases, four studies identified driveways shared with another residence [15, 37, 40, 43] and one study identified having more than one parking area per driveway [15] as being more commonly associated with a driveway-related LSVRO incident.

The twopopulation-based case-control studies from NZ $[15,43]$ showed a 3 -fold increase in risk of driveway-related LSVRO incidents for dwellings with shared driveways [43] or more than one parking area per driveway [15]. The same degree of risk was evident for residences where there was no barrier separating the driveway from children's play areas [43], or where pedestrian access to the property was not separate from the driveway [15]. Driveways that exited onto a local road (compared to a cul-de-sac), driveways of longer length (>12 meters), and driveways that run along the boundary of properties were all associated with a greater than 3 -fold increased risk of an LSVRO incident [15].

\subsubsection{Vehicle Risk Factors}

(1) Type of Vehicle. Twenty six out of 41 studies investigated the type of vehicle involved in LSVRO incidents. Vehicle classification was not consistent across the studies. Passenger cars were reported to be involved in $18 \%$ to $71 \%$ of LSVRO incidents by twenty one studies; amongst them eight studies $[6,18,23,25-27,30,34]$ specified involvement of sedans (range 19\%-69\%).

Eighteen studies used a classification of four-wheel drive vehicles (4WDs or SUVs) and identified involvement of these vehicles in LSVRO incidents ranging from $8 \%$ to $47 \%$.

Eleven studies identified the proportion of vans involved in LSVRO incidents $[5,6,8,17,24,27,28,34,36,37,40]$ and nine studies $[5,8,17,23,28,32,34,36,40]$ reported on the proportion of trucks or light transport vehicles (e.g., utility or pick-up vans) involved in LSVRO events (17\% to $45 \%)$. Five studies combined the proportion of LSVRO incidents due to different vehicle types as follows: SUV and trucks [42], 4WD trucks and jeeps [5], 4WD and light commercial vehicles [13, 18], and SUV, vans, and trucks [14].

(2) Direction of Vehicle. Twenty six out of 41 studies examined vehicle direction at the time of LSVRO incident. Reversing vehicles accounted for varying proportions of LSVRO incidents across the 26 studies, ranging from $19 \%$ to $86 \%$. Fourteen studies $[6,7,12,13,16,18,20,21,23,24,30,32,34,44]$ found that reversing vehicles accounted for more than $50 \%$ of incidents (range 26\%-87\%). 


\subsection{Behavioural Factors}

3.4.1. Child Behavior. Eleven out of 41 studies described the activity of the child at the time of the LSVRO incident $[8,11,13,18,19,23,24,26,30,31,37]$. Most commonly the injured child was involved in a "play" activity in the driveway area or was a "pedestrian." Specific child activities prior to the LSVRO incident include playing in driveways or parking lots, playing with other children, playing under or behind parked cars, or playing within a vehicle, setting it in motion, and injuring a second child (external to, or fallen from, the vehicle).

3.4.2. Driver Awareness of Children. Four studies discussed driver awareness $[6,21,23,37]$ of children involved in LSVRO incidents. Three studies reported that the majority of drivers were unaware of the presence of the child prior to the incident (range 58\%-61\%) [6, 21, 37]. Hsiao et al. [37] reported that $20 \%$ of drivers involved in a driveway LSVRO incident actively checked where the child was and surveyed the driveway before moving the vehicle.

3.4.3. Adult Supervision. Six studies reported adult supervision of the child during the LSVRO incident $[18,21,23$, 24, 30,31]. Agran and colleagues [21] noted that there was no adult supervision in 55\% of driveway LSVRO incidents and that $36 \%$ of these children were injured while they were with other children, and the remaining 19\% were alone at the time of the incident. In a survey of caregivers of children involved in driveway incidents, 58\% perceived a lack of parental supervision as a contributing factor for the injury of their children [18]. In a recent report from New South Wales, $58 \%$ of carers did not know how the child came to be in the path of vehicle. In $33 \%$ of cases the children were with family members at the time of the incident and in $29 \%$ of cases "bystanders" observed the incident and tried to intervene [23].

3.5. Temporal Characteristics. Of the 41 studies, 18 investigated temporal characteristics, either time of day or week. Eight studies reported that LSVRO incidents most commonly occurred during late afternoon and early evening $(3 \mathrm{pm}-$ $8 \mathrm{pm})[5,12,13,17,24,37,40,44]$. Three studies $[6,22$, 24] reported a higher frequency on weekends, compared to weekdays.

\section{Discussion}

This systematic review provides a current assessment of antecedent factors associated with paediatric LSVRO injury and mortality and includes unpublished sources (such as government and commissioned reports) as well as peer-reviewed literature. This review highlights considerable variability in the reporting of risk factors for LSVRO incidents in children. A review of this topic is further complicated by the lack of a standard definition of LSVRO, limited reporting of nontraffic events in many countries, and the variability of case inclusion in the identified studies. All but two studies included in the review were conducted in three countries; the USA, Australia, or NZ. It is likely that cultural, vehicular, environmental, and behavioural factors influence the pattern of LSVRO incidents in each country. Although there are some consistent risk factors identified across many of the studies, it is difficult to generalize study findings beyond the study populations and even more problematic to extrapolate findings to middle- or lower-income countries. For example, there were no studies of LSVRO identified for regions in Asia and Africa where vehicular, environmental, and behavioural factors are likely to differ from studies in the USA, Australia, or NZ.

The literature on LSVRO incidents in children is dominated by case-series studies (38 of 41 studies) describing a range of possible sociodemographic, vehicular, environmental, and behavioural risk factors, and there is a paucity of controlled epidemiological studies validating these risk factors. Only two population-based case-control studies from one city (Auckland) in NZ [15, 43] and one population-based aggregate cross-sectional study [17] were identified. LSVRO may be an outcome more suited to descriptive case-series analysis given that it is a rare injury event, not routinely identified in coded surveillance systems, and with seemingly straightforward mechanisms. However populationbased studies with comparator groups more reliably inform policy and prevention approaches, as such studies enable estimates of relative and attributable risk and test whether distributions of risk factors (particularly sociodemographic factors, driveway and housing characteristics, and vehicle types) are similar or different in children not experiencing LSVRO.

The most commonly identified location for LSVRO incidents across all studies has consistently been the domestic driveway. However, it is not clear from the published literature whether this risk is inherent to the domestic driveway or due to the fact that young children (who are most vulnerable to this injury) spend most of their time in the home environment. However, two case control studies from NZ have specifically examined driveway characteristics. Shepherd et al. [15] identified driveway length, location, traffic speed at exit as well as separation of play areas, and pedestrian access from driveways as risk factors for drivewayrelated LSVRO incidents. Whether these risk factors (in themselves somewhat determined by urban development, housing design, and topography) are unique to the city of Auckland, where both studies were conducted, requires further investigation.

The most consistent LSVRO risk factors identified across all studies for this review were child's age $<5$ years, male gender of child, and vehicle reversing at the time of the incident. Vulnerability of younger children $(<5$ years) to LSVRO incidents is likely to be due to a combination of rapidly developing mobility [12], and lack of perception of danger at this age, as well as anthropometric factors (such as height and weight relative to the vehicle). The higher frequency of LSVRO incidents involving young boys compared to girls reported in some studies may be due to differences in genderrelated play activity and parental/carer risk perception which may be more likely to place boys in driveways and other outside areas. 
The majority of studies that examined vehicle direction reported a higher proportion of LSVRO incidents involving reversing vehicles. The risk associated with reversing vehicles may in part be due to poor rear visibility in many vehicle types and models. However, forward visibility is also restricted in many vehicles. The environmental design feature of driveways and parking spaces, where vehicles predominantly nose-in on arrival and reverse out when leaving, may also contribute to the proportion of incidents involving reversing vehicles. Young children are likely to follow family members to vehicular areas when someone is leaving the residence. Risk associated with departing versus arriving vehicles has not been examined in the literature to date.

The relative contribution of $4 \mathrm{WD}$ or heavier vehicles to LSVRO incidents is difficult to gauge from studies considered for this review, due to the variability in classification and reporting of vehicle type. It is likely that any risk associated with such vehicles is due to both visibility to the front and rear of the vehicle as well as height and weight of the vehicle relative to the child's body, with smaller children more likely to go under taller vehicles without the driver seeing the child or noticing an impact. Many vehicles regardless of size or type have significant limitations to their forward and rearward visibility. The driver's rearward view whilst reversing is further complicated by a driver's physical limitations to turning and aberrations and blind spots when viewing the vehicle path in mirrors. Many vehicles currently on the market have reversing aids such as ultrasound sensors with alarms and rear cameras. Driver behaviour, in the use and interpretation of information from these devices, remains an important component in the control of the vehicle [50]. This review did not identify any studies that examined driver behaviour while reversing or the use of reversing aids as a separate point for analysis.

In a small number of studies, low socioeconomic status was associated with a higher proportion of LSVRO injury in children. Low socio-economic status is interrelated with other risk factors such as living in rental premises, shared driveways, a higher number of children in a household, low parental supervision, low parental education, and ethnicity. The best evidence for risk due to low SES status comes from a case-control study from Auckland, NZ [43]. It is not clear from the current literature whether this risk can be extrapolated to other localities.

In this review, the driver was most commonly identified as being someone known to the child. This is particularly so for residential driveway LSVRO incidents, where the incident usually involved a parent or other family member as driver. Again, this finding is most likely explained by the frequency with which certain driver groups access the residence, with parents overrepresented. It is not clear from current studies whether there are gender or age differences in driver behaviour that might further contribute to risk. Identification of higher LSVRO risk for drivers exposed to young families allows targeted interventions for safer vehicle selection and driver behaviour. The high proportion of family members involved as drivers in LSVRO incidents also highlights a need for further exploration of the psychological impact of these incidents on families.

\subsection{Implications}

4.1.1. Environmental Factors. Several modifiable environmental risk factors have been identified in this review and include residential factors (house design, driveway design) and road factors (road network design). The strongest evidence exists for driveway-related LSVRO risk associated with long, shared driveways with direct child access and multiple vehicular and pedestrian users [15]. Currently, this evidence is limited to studies that originate from one city in NZ [15, 43]. Several studies have called for physical separation of driveways from children's play areas [7, 9, 13, 37, 38, 40, 43], separate pedestrian access to footpaths $[8,15,30]$, and circular driveways $[8,13]$. The implementation of the above strategies requires intervention from policy regulators through design and planning stages to construction. This requires long-term government and industry commitment to implement and is only likely to affect risk in new or recently renovated residences.

4.1.2. Vehicle Factors. Vehicle factors (vehicle size, type, design, and visibility) have all been discussed as potential risk factors for LSVRO incidents. However, there have been no studies to date that effectively evaluate vehicular risk factors. Although "4WDs" may be overrepresented in some LSVRO case series, what is needed is an estimate of exposure of families with young children to different types of vehicles in order to establish a clear risk association. It is likely that 4WDs and SUVs are popular choices for family vehicles, particularly where there is more than one child.

Rear visibility is an independently modifiable risk factor, through the use of reversing aids $[7-9,13,16,17,20,30]$. It is likely that insurance and market influence will drive vehicle manufacturers to make rear visibility aids standard rather than optional features with new vehicles. In part, this has been driven by consumer awareness groups, with some presenting results of comparative tests for rearward and forward visibility of vehicles commonly available on the market [51, 52]. At present, it is possible to retrofit rear visibility aids to many models of vehicle. What is not clear is to what degree standardization of rear visibility aids will affect the pattern and incidence of paediatric LSVRO incidents as there is also a significant behavioural component to the use and interpretation of information from these aids [50]. As with other safety innovations (seat belts, crumple zones, and airbags) emerging knowledge relating to car visibility indexes is likely to be incorporated into future car design, but this is a slower process. A proposition is underway in the United States for a new safety regulation to improve rearward visibility in every new vehicle by year 2014 [53]. A recent study from USA provides some evidence suggesting that reversing cameras when used appropriately (drivers glance at the system at the appropriate time) can successfully mitigate the occurrence of backing crashes into static objects, particularly when paired with an appropriate audible warning system [54].

It is not currently clear which performance requirements for rear visibility aids (location of the viewing screen, location of the camera, number of viewing screens and cameras, and 
field of camera view) would optimize the driver's rear view throughout the entire reversing process, for clearly the aid can only be effective if the driver is looking in the screen and can see the child. Similarly, due to the limitations of driver reaction time, rear visibility aids may not prevent LSVRO incidents where a child steps into the immediate path of a reversing vehicle.

More recent technological developments involve automated pedestrian crash avoidance systems, with some operating to the front of the vehicle and some to the rear $[55,56]$. Again, some of these systems currently have room for human error as they can be overridden if the driver believes the vehicle to be stopping due to interference (terrain, landscaping).

4.1.3. Behaviour Modification and Education. Few studies to date have reported on adult behavioural factors associated with LSVRO incidents $[18,31,37]$. A recent Australian survey reported that $77 \%$ of caregivers of children indicated that the driveway was a safe place, with more than half of the respondents sometimes using the driveway as a play area for children [57].

Government and advocacy organizations have attempted to raise awareness of risk factors associated with LSVRO incidents through print, television, and Internet sites [5860]. These awareness campaigns are aimed at changing driver behaviour around several key messages: visually checking around the vehicle before moving, not allowing children to play within the vehicle, keeping children restrained within the moving vehicle, and never leaving children unattended in a vehicle. Again, more recent technological developments may reduce the risk of a child inadvertently releasing the handbrake, with some vehicles utilizing electronic handbrakes that require a special override manoeuvre for release when the driver seat belt is not engaged.

As with any campaign aimed at changing behaviour, it is challenging to attain broad audience attention, and even more challenging to alter behaviour. This review has demonstrated that the majority of drivers involved in LSVRO incidents are family members or caregivers of the child; therefore, a targeted intervention may be more cost effective. However, even where there is awareness of the risks, supervisor and driver behaviour is likely to be affected by extraneous and competing factors, such as time pressure, distractions, and fatigue.

It is unlikely that an intervention aimed at child behavioural change to prevent LSVRO injury will significantly reduce injury in the peak age group (toddlers). Most toddlers do not have the perceptual skills to implement strategies [61] and the majority of incidents occur in a domestic setting, where they are unlikely to perceive risk despite direct instruction. A similar phenomenon is observed with toddler home pool immersion [62].

\section{Conclusion}

This study has reviewed available peer-reviewed and grey literature on LSVRO injuries in children and compared sociodemographic, vehicular, environmental, and behavioural factors reported within those studies. Most of the studies reviewed were descriptive case-series studies. The two population-based case-control studies that have been conducted have been restricted to driveway-related LSVRO incidents in one city and shown that there are sociodemographic (SES status) and environmental (driveway design, road design, and pedestrian access) risk factors associated with LSVRO injury. Additional studies employing analytic study designs together with standardised reporting and surveillance will improve upon this evidence base. Having started to identify modifiable risk factors, studies now need to be directed at implementing and evaluating interventions.

\section{Conflict of Interests}

No conflict of interests is declared.

\section{Acknowledgment}

This project was funded by the Queensland Injury Prevention Council (Queensland Health), Queensland, Australia (Project ID: 57537).

\section{References}

[1] A. Wazana, P. Krueger, P. Raina, and L. Chambers, "A review of risk factors for child pedestrian injuries: are they modifiable?" Injury Prevention, vol. 3, no. 4, pp. 295-304, 1997.

[2] D. Eldridge, Injury Among Young Australians, Australian Institute of Health and Welfare, Canberra, Australia, 2008, http://www.aihw.gov.au/WorkArea/DownloadAsset.aspx?id $=6442452801$.

[3] F. K. Winston, N. Kassam-Adams, C. Vivarelli-O'Neill et al., "Acute stress disorder symptoms in children and their parents after pediatric traffic injury," Pediatrics, vol. 109, no. 6, article e90, 2002.

[4] L. Wijngaards-de Meij, M. Stroebe, H. Schut et al., "Couples at risk following the death of their child: predictors of grief versus depression," Journal of Consulting and Clinical Psychology, vol. 73, no. 4, pp. 617-623, 2005.

[5] R. J. Brison, K. Wicklund, and B. A. Mueller, "Fatal pedestrian injuries to young children: a different pattern of injury," The American Journal of Public Health, vol. 78, no. 7, pp. 793-795, 1988.

[6] P. Robinson and T. Nolan, "Paediatric slow-speed non-traffic fatalities: Victoria, Australia, 1985-1995," Accident Analysis and Prevention, vol. 29, no. 6, pp. 731-737, 1997.

[7] M. L. Silen, E. R. Kokoska, D. G. Fendya, A. G. Kurkchubasche, T. R. Weber, and T. F. Tracy, "Rollover injuries in residential driveways: age-related patterns of injury," Pediatrics, vol. 104, no. 1, article e7, 1999.

[8] S. J. Fenton, E. R. Scaife, R. L. Meyers, K. W. Hansen, and S. D. Firth, "The prevalence of driveway back-over injuries in the era of sports utility vehicles," Journal of Pediatric Surgery, vol. 40, no. 12, pp. 1964-1968, 2005.

[9] D. A. Partrick, D. D. Bensard, E. E. Moore, M. D. Partington, and F. M. Karrer, "Driveway crush injuries in young children: a highly lethal, devastating, and potentially preventable event," Journal of Pediatric Surgery, vol. 33, no. 11, pp. 1712-1715, 1998.

[10] H. Kravitz and A. Korach, "Deaths due to car driveway accidents," Illinois Medical Journal, vol. 126, article 688, 1964. 
[11] M. J. Bell, J. L. Ternberg, and R. J. Bower, "Low velocity vehicular injuries in children. "Run-over" accidents," Pediatrics, vol. 66, no. 4, pp. 628-631, 1980.

[12] D. G. Winn, P. F. Agran, and D. N. Castillo, "Pedestrian injuries to children younger than 5 years of age," Pediatrics, vol. 88, no. 4, pp. 776-782, 1991.

[13] A. J. A. Holland, R. W. Y. Liang, S. J. Singh, D. N. Schell, F. I. Ross, and D. T. Cass, "Driveway motor vehicle injuries in children," Medical Journal of Australia, vol. 173, no. 4, pp. 192-195, 2000.

[14] R. Stark, S. Lee, A. Neville, B. Putnam, and S. Bricker, "Common denominators in death from pediatric back-over trauma," The American Surgeon, vol. 77, no. 10, pp. 1420-1422, 2011.

[15] M. Shepherd, P. Austin, and J. Chambers, "Driveway runover, the influence of the built environment: a case control study," Journal of Paediatrics and Child Health, vol. 46, no. 12, pp. 760767, 2010.

[16] C. Nhan, L. Rothman, M. Slater, and A. Howard, "Back-over collisions in child pedestrians from the canadian hospitals injury reporting and prevention program," Traffic Injury Prevention, vol. 10, no. 4, pp. 350-353, 2009.

[17] K. A. Pinkney, A. Smith, N. C. Mann, G. D. Mower, A. Davis, and J. M. Dean, "Risk of pediatric back-over injuries in residential driveways by vehicle type," Pediatric Emergency Care, vol. 22, no. 6, pp. 402-407, 2006.

[18] A. J. A. Holland, F. I. Ross, P. Manglick, F. E. Fahy, and D. T. Cass, "Driveway motor vehicle injuries in children: a prospective review of injury circumstances," Medical Journal of Australia, vol. 184, no. 6, article 311, 2006.

[19] Centers for Disease Control, "Non fatal motor-vehicle-related backover injuries among children-United States, 2001-2003," Morbidity and Mortality Weekly Report, vol. 54, no. 6, pp. 144146, 2005.

[20] J. M. Mayr, C. Eder, J. Wernig, D. Zebedin, A. Berghold, and S. H. Corkum, "Vehicles reversing or rolling backwards: an underestimated hazard," Injury Prevention, vol. 7, no. 4, pp. 327328, 2001.

[21] P. F. Agran, D. G. Winn, and C. L. Anderson, "Differences in child pedestrian injury events by location," Pediatrics, vol. 93, no. 2, pp. 284-288, 1994.

[22] I. Roberts, R. Norton, R. Dunn, I. Hassall, and T. Lee-Joe, "Environmental factors and child pedestrian injuries," Australian Journal of Public Health, vol. 18, no. 1, pp. 43-46, 1994.

[23] NSW Child Death Review Team, NSW Child Death Review Team Annual Report 2011, 2012, http://staging.hqsc.sites.silverstripe.com/assets/CYMRC/Publications/low-speed-report.pdf.

[24] N. Baker and B. White, Low Speed Run Over Mortality, Child and Youth Mortality Review Committee, Wellington, New Zealand, 2011, http://staging.hqsc.sites.silverstripe.com/assets/ CYMRC/Publications/low-speed-report.pdf.

[25] B. Griffin, K. Watt, B. Wallis, L. Shields, and R. Kimble, "Paediatric low speed vehicle run-over fatalities in Queensland," Injury Prevention, vol. 17, no. 1, pp. i10-i13, 2011.

[26] R. W. Byard and L. L. Jensen, "Toddler run-overs-a persistent problem," Journal of Forensic and Legal Medicine, vol. 16, no. 4, pp. 202-203, 2009.

[27] Commission for Children and Young People and Child Guardian, Investigation into Low Speed Run-Overs in Queensland, Commission for Children and Young People and Child Guardian, Brisbane, Australia, 2007.

[28] National Highway Traffic Safety Administration, Data Collection Study: Deaths and Injuries Resulting from Certain
Non-Traffic and Non-Crash Events, National Highway Traffic Safety Administration, US Department of Transportation, Washington DC, USA, 2004, http://www.nhtsa.dot.gov/cars/ problems/studies/nontraffic-noncrash/images/noncrash.pdf.

[29] Queensland Injury Surveillance Unit, Low Speed Run-Overs of Young Children, Queensland Injury Surveillance Unit, Brisbane, Australia, 2003, http://www.qisu.org.au/.

[30] T. Neeman, J. Wylie, R. Attewell et al., Driveway Deaths: Fatalities of Young Children in Australia as a Result of LowSpeed Motor Vehicle Impacts, Department of Transport and Regional Services, Australian Transport Safety Bureau, 2002, http://www.infrastructure.gov.au/roads/safety/publications /2002/Driveway_deaths.aspx.

[31] A. Williamson, P. Irvine, and S. Sadural, Analysis of Motor Vehicle-Related Fatalities Involving Children Under the Age of Six Years (1995-2000), University of New South Wales, Injury Risk Management Research Centre, Sydney, Australia, 2002.

[32] R. W. Byard, H. Green, R. A. James, and J. D. Gilbert, "Pathologic features of childhood pedestrian fatalities," The American Journal of Forensic Medicine and Pathology, vol. 21, no. 2, pp. 101-106, 2000.

[33] L. M. Olson, D. P. Sklar, L. Cobb, R. Sapien, and R. Zumwalt, "Analysis of childhood pedestrian deaths in New Mexico, 19861990," Annals of Emergency Medicine, vol. 22, no. 3, pp. 512-516, 1993.

[34] T. M. Rice, R. B. Trent, K. Bernacki et al., “Trauma center-based surveillance of nontraffic Pedestrian injury among California children," Western Journal of Emergency Medicine, vol. 13, no. 2, pp. 139-145, 2012.

[35] Queensland Trauma Registry, Queensland Trauma Review: 53 Children Admitted to Hospital After Being Injured by Vehicles in Home Driveways, Centre of National Research on Disbaility and Rehabilitation Medicine, University of Queensland, 2010, http://www.uq.edu.au/conrod/docs/Feb2010-DrivewayRunOvers.pdf.

[36] J. Hunter, H. M. Poulgrain, and M. Campbell, Accidental Child Driveway Runovers: Exploring Waikato Data and the Efficacy of Existing Responses, Summer Research Scholarship, The University of Waikato, 2009, http://researchcommons.waikato .ac.nz/bitstream/handle/10289/3700/CAPFNZ_SRS_2009.pdf? sequence $=1$.

[37] K. H. Hsiao, C. Newbury, N. Bartlett, R. Dansey, P. Morreau, and J. Hamill, "Paediatric driveway run-over injuries: time to redesign?” New Zealand Medical Journal, vol. 122, no. 1298, pp. 17-24, 2009.

[38] J. Davey, G. A. Dingle, M. J. Clark et al., "The prevalence and characteristics of paediatric driveway accidents in Queensland," The Journal of the Australasian College of Road Safety, vol. 18, no. 2, pp. 34-40, 2007.

[39] Queensland Injury Surveillance Unit, Childhood Pedestrian Injury in Queensland, Queensland Injury Surveillance Unit, Brisbane, Australia, 2004, http://www.qisu.org.au/.

[40] F. Murphy, S. White, and P. Morreau, "Driveway-related motor vehicle injuries in the paediatric population: a preventable tragedy," New Zealand Medical Journal, vol. 115, no. 1160, article U148, 2002.

[41] C. Di Scala, R. Sege, and G. Li, "Outcomes of pediatric pedestrian injuries by locations of event," Annual Proceedings/ Association for the Advancement of Automotive Medicine, vol. 45, pp. 241-250, 2001. 
[42] E. P. Nadler, A. P. Courcoulas, M. J. Gardner, and H. R. Ford, "Driveway injuries in children: risk factors, morbidity, and mortality," Pediatrics, vol. 108, no. 2, pp. 326-328, 2001.

[43] I. Roberts, R. Norton, and R. Jackson, "Driveway-related child pedestrian injuries: a case-control study," Pediatrics, vol. 95, no. 3, pp. 405-408, 1995.

[44] I. Roberts, A. Kolbe, and J. White, "Non-traffic child Pedestrian injuries," Journal of Paediatrics and Child Health, vol. 29, no. 3, pp. 233-234, 1993.

[45] M. R. Stevenson, S. K. Lo, B. A. Laing, and K. D. Jamrozik, "Childhood pedestrian injuries in the Perth metropolitan area," Medical Journal of Australia, vol. 156, no. 4, pp. 234-238, 1992.

[46] P. Godbole, D. C. Crabbe, and M. D. Stringer, "Four children crushed in their driveways," Journal of the Royal Society of Medicine, vol. 94, no. 6, pp. 294-296, 2001.

[47] T. Thinakararajan and N. Buxton, "Reversing motor vehicle injuries: a preventable tragedy," Journal of the Royal Society of Medicine, vol. 101, no. 4, pp. 163-164, 2008.

[48] M. S. Wright, "Nonambulatory "Pedestrians": infants injured by motor vehicles in driveways," Clinical Pediatrics, vol. 37 , no. 8 , pp. 515-518, 1998.

[49] A. C. Duhaime, M. Eppley, S. Margulies, K. L. Heher, and S. P. Bartlett, "Crush injuries to the head in children," Neurosurgery, vol. 37, no. 3, pp. 401-407, 1995.

[50] M. Paine and M. Henderson, Devices to Reduce the Risk to Young Pedestrians from Reversing Motor Vehicles, Motor Accident Authority of New South Wales, Sydney, Australia, 2001.

[51] CHOICE, "Car Rear Visibility Database: How Well Can You See out of the Back of Your Car?" 2013, http://www.choice.com.au/ reviews-and-tests/travel-and-transport/cars/safety-and-advice/ car-rear-visibility.aspx.

[52] National Roads \& Motorists' Association Insurance, "Reversing Visibility Results," 2011, http://www.nrma.com.au/carreversing-visibility-tables.

[53] National Highway Traffic Safety Administration (NHTSA), Federal Motor Vehicle Safety Standard, Rearview Mirrors, Federal Motor Vehicle Safety Standard, Low-Speed Vehicles Phase-in Reporting Requirements, 2010, http://www.regulations .gov/\#!documentDetail,D=NHTSA-2010-0162-0002.

[54] D. S. Hurwitz, A. Pradhan, D. L. Fisher et al., "Backing collisions: a study of drivers' eye and backing behaviour using combined rear-view camera and sensor systems," Injury Prevention, vol. 16, no. 2, pp. 79-84, 2010.

[55] Surveillance Guard Co. Ltd., "Surveillance Guard Co. LtdReverse Alert," 2012, http://www.svgltd.com/reverse.

[56] Euro NCAP, "Reward 2010-Volvo City Safety", The European New Car Assessment Programme, 2012, http://www.euroncap .com/rewards/volvo_city_safety.aspx.

[57] Institute of Biomedical Innovation, Take a SEC to Prevent Driveway Run-Over Tragedies, Centre for Accident Research and Road Safety-Queensland, 2012, http://www.ihbi.qut.edu .au/about/news/news-event.jsp?news-event-id=37747.

[58] Parliamentary Travelsafe Committee, "Investigation into child deaths and injuries from low speed vehicle run-overs," Report No. 50, Parliamentary Travelsafe Committee, Queensland Parliament, Brisbane, Australia, 2007.

[59] Auburn City Council, Where Are Your Kids? Child Safety in Your Driveway, Auburn City Council, Auburn, Australia, 2009, http://www.auburn.nsw.gov.au/Explore/RoadSafety/RoadSafetyDocuments/Where\%20Are\%20Your\%20Kids.pdf.
[60] Kids and Cars, "There Are 62 Children Behind This Vehicle," Kids and Cars, 2011, http://www.kidsandcars.org/back-overs .html\#Charts.

[61] R. E. Sapien, J. W. Roux, and L. Fullerton-Gleason, “Children's response to a commercial back-up warning device," Injury Prevention, vol. 9, no. 1, pp. 87-88, 2003.

[62] L. A. Petrass, J. D. Blitvich, and C. F. Finch, "Lack of caregiver supervision: a contributing factor in Australian unintentional child drowning deaths, 2000-2009," Medical Journal of Australia, vol. 194, no. 5, pp. 228-231, 2011. 


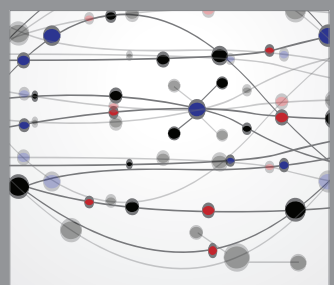

The Scientific World Journal
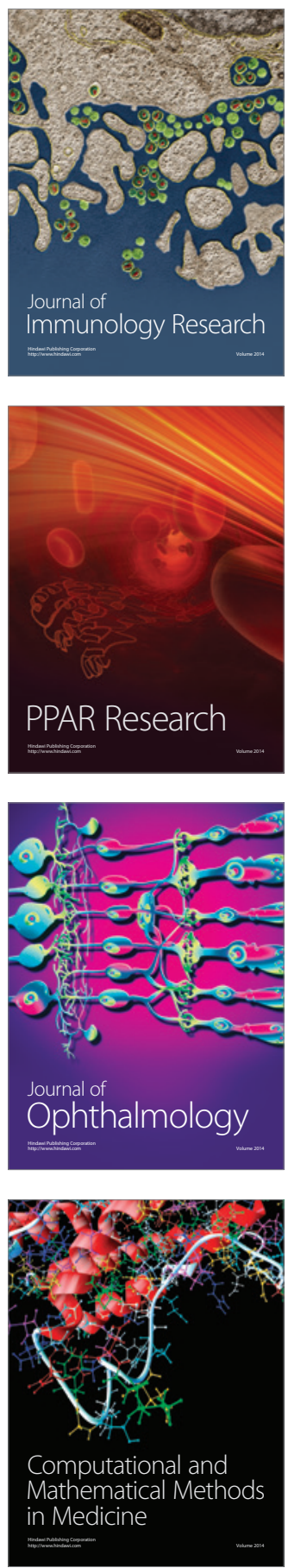

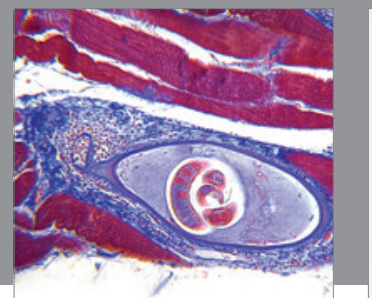

Gastroenterology

Research and Practice
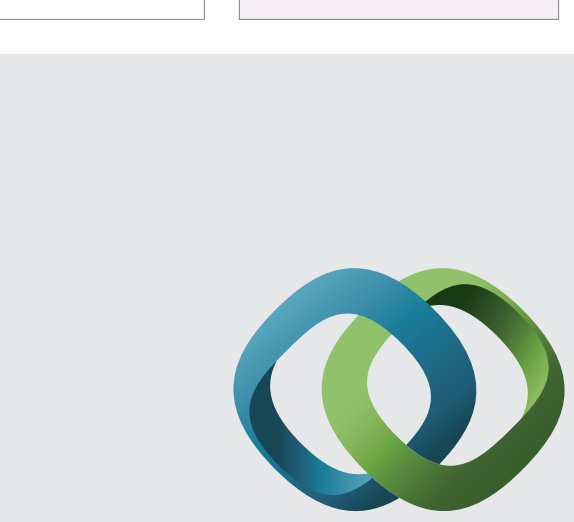

\section{Hindawi}

Submit your manuscripts at

http://www.hindawi.com
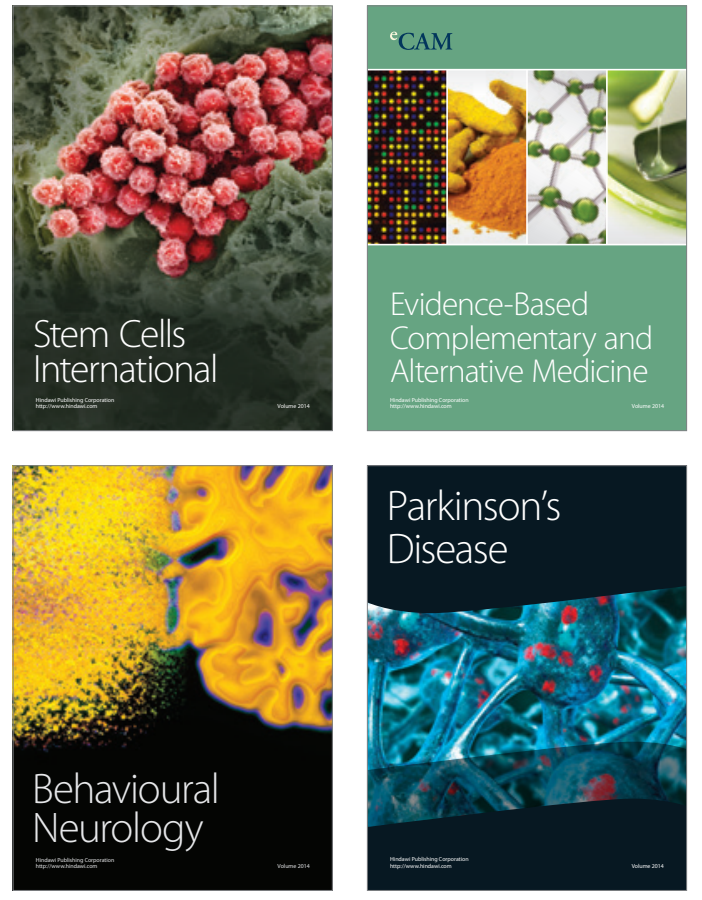
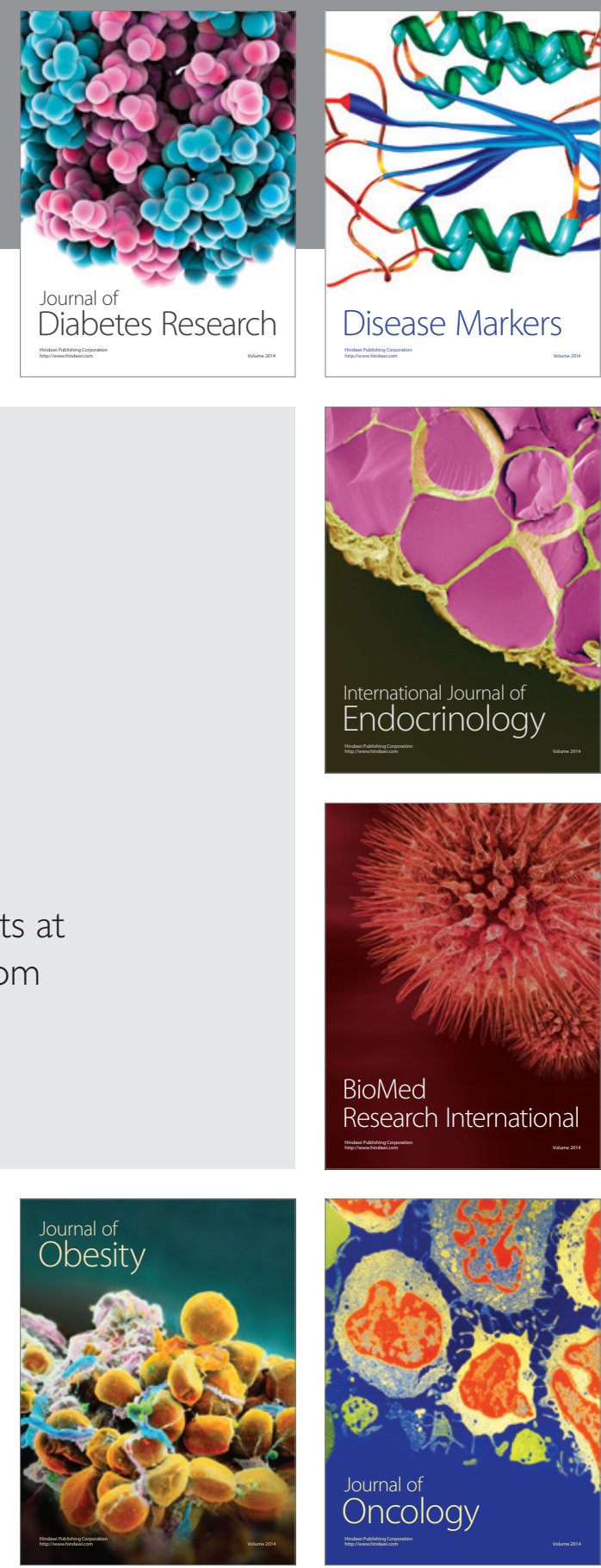

Disease Markers
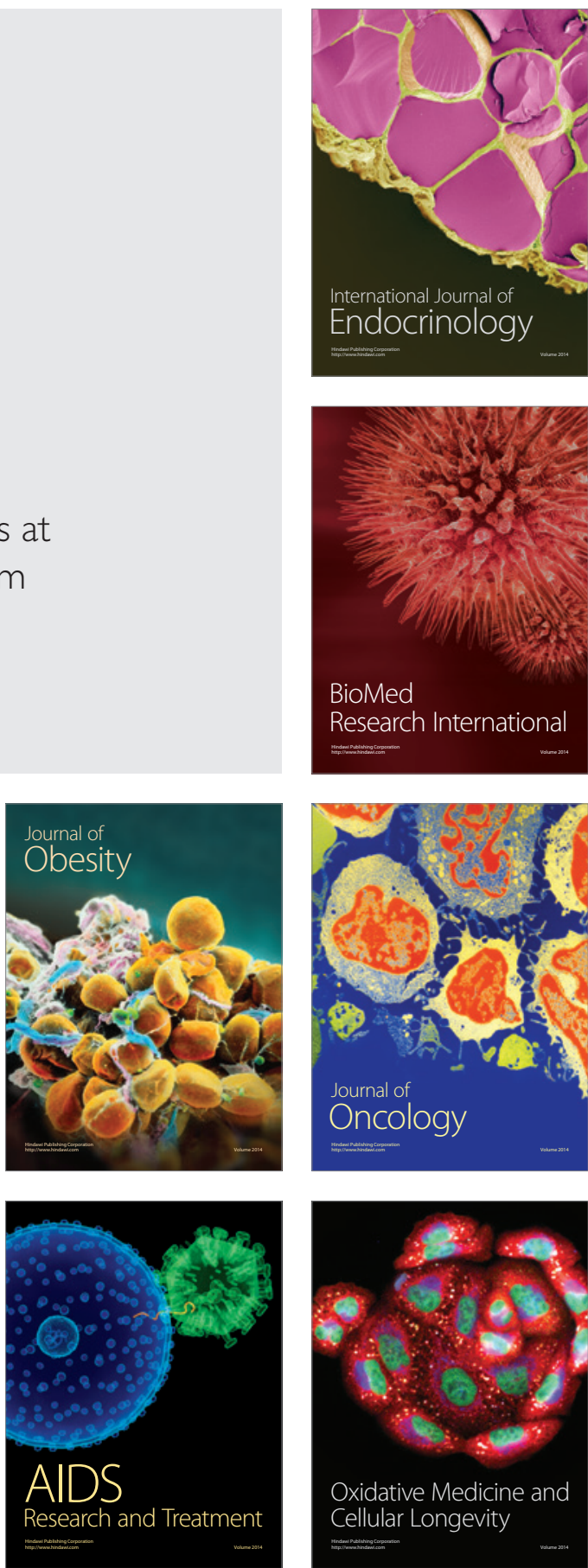